\title{
Características agronômicas de bananeiras tipo Prata sob diferentes sistemas de irrigação
}

\author{
Pedro Ricardo Rocha Marques(1), Sérgio Luiz Rodrigues Donato(2), Marlon Cristian Toledo Pereira(1), \\ Eugênio Ferreira Coelho ${ }^{(3)}$ e Alessandro de Magalhães Arantes ${ }^{(2)}$
}

\begin{abstract}
(1)Universidade Estadual de Montes Claros, Campus Janaúba, Avenida Reinaldo Viana, no2.630, Bico da Pedra, Caixa Postal 91, CEP 39440-000 Janaúba, MG. E-mail: pedrounimontes@yahoo.com.br, marlon.pereira@unimontes.br ${ }^{(2)}$ Instituto Federal de Educação Ciência e Tecnologia Baiano, Campus Guanambi, Distrito de Ceraíma, Caixa Postal 009, CEP 46430-000 Guanambi, BA. E-mail: sergiodonatoeaf@yahoo.com.br, arantes2005@yahoo.com.br ${ }^{(3)}$ Embrapa Mandioca e Fruticultura Tropical, Rua Embrapa, s/no, Caixa Postal 007, CEP 44380-000 Cruz das Almas, BA. E-mail: eugenio@cnpmf.embrapa.br
\end{abstract}

Resumo - O objetivo deste trabalho foi avaliar as características agronômicas de bananeiras tipo Prata em três ciclos de produção, sob diferentes sistemas de irrigação, em condições semiáridas. Adotou-se o delineamento experimental de blocos ao acaso, com seis tratamentos em arranjo fatorial 3x2: três sistemas de irrigação aspersão convencional, microaspersão e gotejamento - e dois genótipos - 'Prata-Anã' e PA42-44. Utilizaram-se quatro repetições e parcelas com seis plantas úteis. À época do florescimento, avaliaram-se: altura de planta; perímetro de pseudocaule; número de folhas vivas; comprimento e largura da terceira folha; área foliar total e índice de área foliar. À colheita, avaliaram-se: massa do cacho e das pencas; massa média das pencas; massa das três primeiras pencas; número de pencas e de frutos; massa, comprimento e diâmetro de fruto; e número de folhas vivas. O sistema de irrigação por gotejamento proporciona menor vigor, expresso pelo porte e perímetro do pseudocaule, para bananeiras tipo Prata, em comparação aos sistemas de irrigação por aspersão e microaspersão. A 'Prata-Anã' apresenta maior número de frutos e de pencas por cacho, enquanto seu híbrido PA42-44 apresenta maior massa, comprimento e diâmetro do fruto.

Termos para indexação: Musa, distribuição de água, irrigação pressurizada, triploide AAB, tetraploide AAAB.

\section{Agronomic characteristics of Prata type banana plants under different irrigation systems}

\begin{abstract}
The objective of this work was to evaluate the agronomic characteristics of Prata banana plants during three production cycles, under different irrigation systems, in semi-arid conditions. A randomized block design was adopted with six treatments, in a $3 \times 2$ factorial arrangement: three irrigation systems - conventional sprinkler, microsprinkler and drip - and two genotypes - 'Prata-Anã' and its hybrid PA42-44. Four replicates in plots with six useful plants were used. Plant height, pseudostem perimeter, number of alive leaves, length and width of the third leaf, total leaf area, and leaf area index were evaluated at flowering. Weight of bunch and hands, mean weight of hands, weight of the three first hands, number of hands and fruits per bunches, and weight, length and diameter of fruits and number of alive leaves were evaluated during the harvest season. The drip irrigation system provides smaller vigor to banana Prata, in comparison to conventional and to micro sprinkler systems, as can be seen by the size and perimeter of the pseudostem. The cultivar Prata-Anã shows a larger number of fruit and hands per brunch, while its hybrid PA42-44 shows larger weight, length and fruit diameter.
\end{abstract}

Index terms: Musa, water distribution, pressurized irrigation, triploid AAB, tetraploid AAAB.

\section{Introdução}

O crescimento, o desenvolvimento e a produtividade da bananeira variam com o solo, clima, nível de manejo e genótipo. Para um genótipo expressar o seu potencial biológico em rendimento, necessita-se de manejo tecnológico e ambiente apropriados (Robinson \& Galán Saúco, 2010).
Nas condições semiáridas, ou mesmo nos trópicos úmidos e subtrópicos frios, a bananeira, requer irrigação suplementar às chuvas. Isto ocorre porque, nesses ambientes, a demanda evaporativa frequentemente excede a capacidade da bananeira para extrair água do solo, o que provoca perda de turgor e murcha temporária (Robinson \& Galán Saúco, 2010). Assim, o manejo eficiente da irrigação é crucial para a obtenção

Pesq. agropec. bras., Brasília, v.46, n.8, p.852-859, ago. 2011 
de altos rendimentos em bananeira (Paull \& Duarte, 2011).

No Brasil, na maioria dos plantios comerciais irrigados, predominam os sistemas de irrigação por aspersão convencional subcopa, por microaspersão e por gotejamento (Almeida et al., 2003; Coelho et al., 2003). Os sistemas de irrigação possuem características específicas, que podem influenciar o crescimento e o desenvolvimento das plantas e afetar a produção. Esses sistemas se diferenciam no modo de aplicação da água sobre a superfície do solo, na área de molhamento, na uniformidade de distribuição de água na superfície e no perfil do solo. Além disso, tais sistemas sofrem influência dos fatores climáticos, particularmente o vento, de maneira diferenciada na distribuição de água sobre o solo, que é maior em sistemas de aspersão e microaspersão (Yazar, 1984).

As variações consideradas entre os sistemas de irrigação acarretam mudanças na distribuição vertical e horizontal das raízes no solo, o que influencia a maior ou menor área de absorção de água e nutrientes, e tem consequências para o fluxo difusivo de nutrientes no solo que causa alterações na fisiologia da bananeira. Isso pode ser expresso por mudança nas relações parte aérea-raiz (Taiz \& Zeiger, 2009), pelo maior teor de nutrientes nas folhas e pela maior produtividade de um determinado genótipo (Donato et al., 2010).

Genótipos de bananeira cultivados sob diferentes sistemas de irrigação, no mesmo ambiente e na mesma condição de cultivo, podem apresentar mudanças nas características fenotípicas (Donato et al., 2010). Essas mudanças podem representar incrementos ou decréscimos no crescimento vegetativo e no rendimento dos genótipos e advêm das diferenças proporcionadas pelos sistemas de irrigação, da variabilidade existente entre os genótipos ou podem resultar da interação genótipo x ambiente (Robinson \& Galán Saúco, 2010).

Apesar do extenso número de trabalhos sobre avaliação de genótipos (Azevedo et al., 2010) e irrigação (Garcia, 2000; Almeida et al., 2003; Figueiredo et al., 2006; Fernandes et al., 2008; Silva et al., 2009; Sant'ana, 2011), são raros os estudos sobre diferentes genótipos de bananeira, em diferentes sistemas de irrigação.

O conhecimento das expressões das características fenotípicas, resultante da combinação de cultivares e sistemas de irrigação, sob determinadas condições de solo, clima e manejo podem fornecer subsídios para a identificação do arranjo mais adequado para o incremento da qualidade e quantidade da produção.

O objetivo deste trabalho foi avaliar as características agronômicas de bananeiras tipo Prata, em três ciclos de produção (mãe, filha e neta), sob diferentes sistemas de irrigação, nas condições semiáridas do sudoeste da Bahia.

\section{Material e Métodos}

O experimento foi implantado em Latossolo Vermelho-Amarelo distrófico típico, A fraco, de textura média, fase caatinga hipoxerófila, relevo plano a suave-ondulado (Jacomine et al., 1979; Santos et al., 2006). A área localiza-se no Instituto Federal Baiano de Educação, Ciência e Tecnologia, Campus Guanambi, $\mathrm{BA}$, a $14^{\circ} 13^{\prime} 30^{\prime \prime} \mathrm{S}, 42^{\circ} 46^{\prime} 53^{\prime \prime} \mathrm{W}$, à altitude de $525 \mathrm{~m}$, com médias anuais de precipitação de $663,69 \mathrm{~mm}$ e temperatura média de $26^{\circ} \mathrm{C}$. O clima do local é do tipo Aw, segundo a classificação de Köppen.

No plantio, em 31/1/2008, utilizaram-se mudas micropropagadas em espaçamento de 3,0x2,5 m. A implantação e os tratos culturais seguiram as recomendações para a cultura, conforme Rodrigues et al. (2008). A água utilizada foi de poço tubular, classificada como $\mathrm{C}_{3} \mathrm{~S}_{1}$ - água com alta salinidade e baixa concentração de sódio (Ayers \& Westcot, 1991) -, cujas características químicas são $\mathrm{pH} 6,6$, condutividade elétrica de $0,82 \mathrm{dS} \mathrm{m}^{-1}$, e concentrações, em $\mathrm{mg} \mathrm{L}^{-1}$, de: $\mathrm{Ca}^{2+}, 3,53 ; \mathrm{Mg}^{2+}, 2,23 ; \mathrm{K}^{+}, 0,15 ; \mathrm{Na}^{+}, 3,48 ; \mathrm{Cl}^{-}, 5,20$; $\mathrm{CO}_{3}{ }^{2-}, 0 ; \mathrm{HCO}_{3}^{-}, 4,00$.

No manejo da irrigação dos diferentes sistemas, adotou-se a lâmina de $5,04 \mathrm{~mm}$ por dia, em média. As lâminas aplicadas variaram ao longo do experimento. As irrigações foram realizadas com base na evapotranspiração de referência (ETo), calculada pelo método de Penman-Monteith (Coelho et al., 2009). Os elementos meteorológicos usados nesse modelo - temperatura do ar $\left({ }^{\circ} \mathrm{C}\right)$, umidade relativa do ar $(\%)$, velocidade de vento $\left(\mathrm{m} \mathrm{s}^{-1}\right)$ e radiação solar (MJ m-2 por dia) - foram coletados diariamente em estação meteorológica automática Vantage Pro Integradet Sensor (Davis Instruments, Wayward, CA, EUA) instalada na área. Os coeficientes de cultivo para determinação da ETc foram definidos em função das fases fenológicas da cultura, conforme Coelho et al. (2009). Nos cálculos, foram considerados também os atributos físico-hídricos do solo, determinados por análises laboratoriais, e as vazões dos sistemas de 
irrigação. Na fase de florescimento e de enchimento de cacho, do primeiro ciclo de produção em 2008 (10/9 a 9/11/2008), foram aplicadas lâminas líquidas em quantidades ligeiramente inferiores às da necessidade hídrica da cultura, por problemas operacionais de abastecimento d'água. Também foram registradas nesse período temperaturas máximas superiores a $34^{\circ} \mathrm{C}$.

Utilizou-se o delineamento experimental de blocos ao acaso, com seis tratamentos, em arranjo fatorial $3 \times 2$ e quatro repetições. As parcelas experimentais foram constituídas por seis plantas úteis, dispostas em fileira, com bordadura completa. Os três sistemas de irrigação avaliados foram: aspersão convencional subcopa, microaspersão e gotejamento. Os dois genótipos utilizados foram: 'Prata-Anã', triploide $\mathrm{AAB}$, e seu híbrido PA42-44, tetraploide AAAB, desenvolvido pela Embrapa Mandioca e Fruticultura Tropical.

Os sistemas de irrigação foram: aspersão convencional, irrigação em subcopa, com aspersores setoriais Naandan, modelo 427 1⁄2" (NaanDan Indústria e Comércio de Equipamentos para Irrigação Ltda., Leme, SP, Brasil) macho, com vazão 1.500 L por hora, com bocal de 3,2 $\mathrm{mm}$, em espaçamento de $12 \mathrm{~m}$ entre linhas laterais e $12 \mathrm{~m}$ entre aspersores; microaspersão, com emissores Netafim, modelo autocompensante (Netafim Israel, Kibutz Hatzerim, Israel), com vazão de $70 \mathrm{~L}$ por hora, diâmetro molhado de $6 \mathrm{~m}$, com bocal verde de $1,33 \mathrm{~mm}$, espaçamento de $6 \mathrm{~m}$ entre laterais e $5 \mathrm{~m}$ entre emissores; gotejamento com uma lateral por fileira de planta, com emissores sobrelinha modelo Catif (Plastro Brasil Sistemas de Irrigação, Uberlândia, MG, Brasil), com vazão de 2,3 L por hora, e espaçamento entre laterais de $3 \mathrm{~m}$ e entre emissores de $0,30 \mathrm{~m}$.

As mensurações foram realizadas à época do florescimento e da colheita, nos ciclos de produção das plantas mãe, filha e neta. Avaliaram-se, nas plantas úteis de todas as repetições dos tratamentos, os descritores fenotípicos-padrão conforme Descriptors for banana (1996).

À época do florescimento, mensuraram-se as características vegetativas: altura das plantas, perímetro do pseudocaule, número de folhas vivas, comprimento e largura da terceira folha, área foliar total e índice de área foliar. A quantidade de folhas vivas presentes na planta foi avaliada também à época da colheita dos cachos. A área foliar total da planta (AFT), expressa em metros quadrados, foi estimada pela equação de regressão linear, ajustada para a 'Prata-Anã' (Zuculoto et al., 2008), $\mathrm{AFT}=0,5187(\mathrm{C}$ x L x N) + 9603,5, $\mathrm{R}^{2}=0,89(\mathrm{p}<0,05)$, em que: $\mathrm{C}$ e $\mathrm{L}$ representam o comprimento largura da terceira folha, respectivamente; $\mathrm{N}$ é o número de folhas vivas; e 0,5187 é o fator de correção. Estimou-se a área foliar total apenas para a planta da touceira representativa do ciclo avaliado. À época da colheita, foram determinados: massa do cacho e das pencas; massa média das pencas; massa da primeira, segunda e terceira pencas; o número de frutos e de pencas por cacho; a massa, o diâmetro e o comprimento do fruto. Essas características foram mensuradas no fruto central da fileira externa de frutos da segunda penca, que foi utilizado como critério de colheita dos cachos, com um calibre mínimo de $32 \mathrm{~mm}$.

Os dados foram submetidos à análise de variância. As interações significativas foram desdobradas, e as médias comparadas pelo teste de Tukey, a $5 \%$ de probabilidade. Nos casos em que não ocorreu interação, analisaram-se os efeitos dos fatores principais. As médias das características que apresentaram significância para o fator sistemas de irrigação foram comparadas pelo teste de Tukey, e para o fator genótipo, pelo teste $\mathrm{F}$, a $5 \%$ de probabilidade.

\section{Resultados e Discussão}

Ocorreram interações significativas entre genótipos e sistemas de irrigação apenas para a característica número de frutos por penca, no primeiro ciclo, e para massa da segunda penca, e massa média das pencas no segundo ciclo de produção (Tabela 1). No primeiro ciclo de produção, a 'Prata-Anã' apresentou maior número de frutos por penca, em todos os sistemas de irrigação, em comparação à sua progênie, o que evidencia ser uma diferença genética, independentemente do ambiente ou manejo aplicado; fato este confirmado por Lédo et al. (2008) e Donato et al. (2009), que verificaram sob sistemas de irrigação por aspersão e microaspersão, respectivamente, o maior número de frutos por penca para 'Prata-Anã', em comparação ao híbrido PA42-44. A genitora sob gotejamento apresentou menor número de frutos por penca, em comparação aos tratamentos sob aspersão; para o híbrido, o melhor resultado foi sob microaspersão, comparado aos tratamentos sob aspersão convencional. (Tabela 1).

No segundo ciclo, PA42-44 superou a genitora, quanto à massa da segunda penca, e quanto à 
massa média das pencas sob irrigação por aspersão convencional. A 'Prata-Anã' não diferiu quanto às variáveis avaliadas, sob todos os sistemas de irrigação; entretanto, PA42-44 exibiu menor massa da segunda penca e massa média das pencas sob irrigação por gotejamento. Para a massa média das pencas, Lédo et al. (2008) encontraram igualdade entre 'Prata-Anã' e PA42-44 nos dois ciclos de produção.

Os menores valores das características avaliadas, observados de forma geral, sob gotejamento, quando analisados para cada genótipo, podem advir das diferenças entre os tipos de irrigação, como área de molhamento maior nos sistemas por aspersão convencional e microaspersão (Costa et al., 2008) que, provavelmente, proporcionam maior expansão do sistema radicular, com reflexos no crescimento e desenvolvimento da planta.

Os sistemas de irrigação e os genótipos influenciaram as características vegetativas avaliadas, porém não houve interação entre os fatores. As plantas cultivadas sob os sistemas de irrigação por microaspersão e aspersão apresentaram maior altura, em comparação às cultivadas sob gotejamento, nos três ciclos de produção (Tabela 2). Fato semelhante foi registrado quanto ao perímetro de pseudocaule no segundo e terceiro ciclos. Essas variáveis respondem aos fatores ambientais e de manejo e expressam o vigor das plantas. O perímetro do pseudocaule representa o número de folhas emitidas pela planta (Silva et al., 2000) e pode influenciar o número de pencas (Robinson \& Galán Saúco, 2010), enquanto a altura da planta sofre maior influência do manejo e do ambiente (Soto Ballestero, 2008).

As plantas sob gotejamento apresentaram menor comprimento da terceira folha, nos três ciclos, em comparação às plantas sob outros sistemas; ainda quanto à esta variável, as plantas sob aspersão convencional, no primeiro ciclo, e a microaspersão, no segundo e terceiro ciclos, obtiveram maiores valores. O comprimento e a largura da folha e o número de folhas vivas influenciam a área e o índice de área foliar da bananeira, que são dependentes das condições ecológicas e de manejo (Soto Ballestero, 2008).

O número de folhas na colheita, no segundo ciclo de produção, foi maior nas plantas sob microaspersão, em comparação ao de plantas sob gotejamento, e não diferiu do de plantas sob aspersão (Tabela 2), provavelmente pela maior expansão radicular decorrente do uso dos sistemas de aspersão e microaspersão (Costa et al., 2008; Sant'ana, 2011). Entretanto, não houve diferenças no número de folhas ao florescimento, na comparação entre os sistemas de irrigação. Após o florescimento, as plantas com maior área radicular mantêm as folhas por maior tempo, pois cessa a emissão de raízes e folhas, iniciando a senescência desses órgãos e culminando com o amadurecimento do cacho (Soto Ballestero, 2008; Robinson \& Galán Saúco, 2010).

Os valores encontrados nos três sistemas de irrigação são próximos aos dos registrados por Donato et al. (2006), no mesmo local, sob irrigação por aspersão convencional, e são superiores aos constatados por Oliveira et al. (2008), sob sequeiro. A presença de doenças e de fatores climáticos, como excesso de vento, podem afetar o desempenho dessas variáveis, o que explicaria o fato de esses valores serem diferentes. No trabalho de Oliveira et al. (2008), houve incidência de sigatoka, o que explicaria os menores valores do número de folhas; na região de estudo de Donato et al. (2006), apesar do excesso de vento, o número de folhas vivas foi maior e semelhante ao deste trabalho. Não houve diferenças no número de folhas ao florescimento entre os três sistemas de irrigação. A quantidade de folhas registrada neste trabalho atende ao requisito mínimo para o enchimento normal dos cachos em bananeiras tipo Prata (Rodrigues et al., 2009).

Tabela 1. Número de frutos por penca, no primeiro ciclo, e massa da segunda penca e massa média das pencas, no segundo ciclo, dos genótipos de bananeira 'Prata-Anã' e PA42-44, submetidos aos sistemas de irrigação por aspersão convencional, microaspersão e gotejamento ${ }^{(1)}$.

\begin{tabular}{|c|c|c|c|c|c|c|}
\hline \multirow[t]{3}{*}{ Sistema de irrigação } & \multirow{2}{*}{\multicolumn{2}{|c|}{$\frac{\text { Primeiro ciclo }}{\text { Número de frutos por penca }}$}} & \multicolumn{4}{|c|}{ Segundo ciclo } \\
\hline & & & \multicolumn{2}{|c|}{ Massa da segunda penca $(\mathrm{kg})$} & \multicolumn{2}{|c|}{ Massa média das pencas (kg) } \\
\hline & 'Prata-Anã' & PA42-44 & 'Prata-Anã' & PA42-44 & 'Prata-Anã' & PA42-44 \\
\hline Aspersão & $14,75 \mathrm{aA}$ & $11,83 \mathrm{bB}$ & $2,29 \mathrm{bA}$ & $2,90 \mathrm{aA}$ & $2,10 \mathrm{bA}$ & $2,50 \mathrm{aA}$ \\
\hline Microaspersão & $13,90 \mathrm{aAB}$ & $12,90 \mathrm{bA}$ & $2,42 \mathrm{aA}$ & $2,71 \mathrm{aA}$ & $2,23 \mathrm{aA}$ & $2,47 \mathrm{aA}$ \\
\hline Gotejamento & $13,54 \mathrm{aB}$ & $12,01 \mathrm{bAB}$ & $2,41 \mathrm{aA}$ & $2,05 \mathrm{aB}$ & $2,03 \mathrm{aA}$ & $1,73 \mathrm{aB}$ \\
\hline$\overline{\mathrm{CV}}(\%)$ & \multicolumn{2}{|c|}{4,22} & \multicolumn{2}{|c|}{14,58} & \multicolumn{2}{|c|}{14,32} \\
\hline
\end{tabular}

${ }^{(1)}$ Médias seguidas de letras iguais, minúsculas nas linhas e maiúsculas nas colunas, não diferem entre si, pelo teste de Tukey, a $5 \%$ de probabilidade. 
Quanto à área foliar e ao índice de área foliar, as plantas sob microaspersão exibiram maiores valores do que os das plantas sob gotejamento, no segundo e terceiro ciclos de produção, o que era de se esperar, pois a área foliar é proporcional ao número de folhas (Soto Ballestero, 2008; Zuculoto et al., 2008). Em trabalho realizado em área comercial com 'Prata-Anã', sob irrigação localizada, Figueiredo et al. (2006) observaram que os índices de área foliar respondem bem a lâminas de irrigação crescentes, principalmente no segundo ciclo, e os valores encontrados foram muito próximos aos do presente trabalho.

A altura da planta não diferiu entre os genótipos nos três ciclos (Tabela 2). Donato et al. (2006, 2009), Lédo et al. (2008) e Oliveira et al. (2008) encontraram similaridade entre 'Prata-Anã' e PA42-44, o que confirma que esses genótipos têm o mesmo porte. A 'Prata-Anã' apresentou, nos dois primeiros ciclos, maior perímetro de pseudocaule do que PA42-44.
Donato et al. (2006), Lédo et al. (2008) e Oliveira et al. (2008) também observaram maior perímetro de pseudocaule em 'Prata-Anã'. No entanto, Donato et al. (2009) encontraram similaridade entre esses genótipos para essa característica. A despeito disto, percebe-se, pelos resultados do presente trabalho, que essa é uma característica varietal, que também sofre influência ambiental e de manejo.

A 'Prata-Anã' foi superior, no segundo ciclo, quanto ao comprimento e à largura da terceira folha, enquanto PA42-44 apresentou maior comprimento da terceira folha no terceiro ciclo.

Houve diferençasentreos genótipos quantoao número de folhas ao florescimento e à colheita, independentemente dos sistemas de irrigação. A 'Prata-Anã' apresentou mais folhas que o híbrido PA42-44 nos três ciclos. Donato et al. (2006) observaram maior número de folhas em 'Prata-Anã', em comparação a PA42-44. Entretanto, Oliveira et al. (2008) encontraram maior

Tabela 2. Características vegetativas, avaliadas em três ciclos de produção, dos genótipos de bananeira Prata-Anã e PA42-44, submetidos aos sistemas de irrigação por aspersão convencional, microaspersão e gotejamento ${ }^{(1)}$.

\begin{tabular}{|c|c|c|c|c|c|c|c|}
\hline \multirow[t]{2}{*}{ Característica } & \multirow[t]{2}{*}{ Ciclo } & \multicolumn{3}{|c|}{ Sistema de irrigação } & \multicolumn{2}{|c|}{ Genótipo } & \multirow{2}{*}{$\begin{array}{l}\text { CV } \\
(\%)\end{array}$} \\
\hline & & Aspersão & Microaspersão & Gotejamento & 'Prata-Anã' & PA 42-44 & \\
\hline \multirow[t]{3}{*}{ Altura de planta $(\mathrm{cm})$} & Primeiro & $225,48 \mathrm{a}$ & $219,00 \mathrm{a}$ & $200,59 \mathrm{~b}$ & $215,24 a$ & $215,00 \mathrm{a}$ & 5,79 \\
\hline & Segundo & $338,17 \mathrm{a}$ & $335,54 \mathrm{a}$ & $297,76 \mathrm{~b}$ & $321,44 a$ & $326,20 \mathrm{a}$ & 4,28 \\
\hline & Terceiro & $382,02 \mathrm{a}$ & $393,65 \mathrm{a}$ & $329,89 b$ & $359,37 \mathrm{a}$ & $377,67 \mathrm{a}$ & 8,92 \\
\hline \multirow[t]{3}{*}{ Perímetro de pseudocaule $(\mathrm{cm})$} & Primeiro & $63,21 \mathrm{a}$ & $62,08 \mathrm{a}$ & $61,83 a$ & $64,03 a$ & $60,75 b$ & 4,86 \\
\hline & Segundo & $96,19 \mathrm{a}$ & $98,25 \mathrm{a}$ & $86,72 b$ & $97,04 a$ & $90,40 \mathrm{~b}$ & 4,14 \\
\hline & Terceiro & $108,52 \mathrm{a}$ & $112,52 \mathrm{a}$ & $96,53 b$ & $105,95 \mathrm{a}$ & $105,76 \mathrm{a}$ & 7,27 \\
\hline \multirow[t]{3}{*}{ Comprimento da terceira folha $(\mathrm{cm})$} & Primeiro & $174,12 \mathrm{a}$ & $171,48 \mathrm{ab}$ & $158,13 b$ & $170,42 \mathrm{a}$ & $165,40 \mathrm{a}$ & 6,57 \\
\hline & Segundo & $226,97 \mathrm{a}$ & $227,28 \mathrm{a}$ & $203,20 \mathrm{~b}$ & $215,63 \mathrm{a}$ & $222,67 b$ & 4,17 \\
\hline & Terceiro & $234,61 \mathrm{a}$ & $242,77 \mathrm{a}$ & $221,71 b$ & $225,37 \mathrm{~b}$ & $240,69 a$ & 6,33 \\
\hline \multirow[t]{3}{*}{ Largura da terceira folha $(\mathrm{cm})$} & Primeiro & $67,41 \mathrm{a}$ & $66,99 \mathrm{a}$ & $66,70 \mathrm{a}$ & $67,93 a$ & $66,14 a$ & 4,50 \\
\hline & Segundo & $77,94 a$ & $77,01 \mathrm{a}$ & $74,43 a$ & $79,23 \mathrm{a}$ & $73,69 b$ & 5,04 \\
\hline & Terceiro & $79,46 \mathrm{a}$ & $78,28 \mathrm{ab}$ & $75,31 \mathrm{~b}$ & $78,88 \mathrm{a}$ & $76,44 \mathrm{a}$ & 3,91 \\
\hline \multirow[t]{3}{*}{ Número de folhas ao florescimento } & Primeiro & $16,05 \mathrm{a}$ & $15,62 \mathrm{a}$ & $17,06 \mathrm{a}$ & $17,08 \mathrm{a}$ & $15,42 b$ & 6,96 \\
\hline & Segundo & $15,78 \mathrm{a}$ & $16,12 \mathrm{a}$ & $15,55 \mathrm{a}$ & $16,86 \mathrm{a}$ & $14,77 b$ & 6,66 \\
\hline & Terceiro & $17,09 \mathrm{a}$ & $17,69 \mathrm{a}$ & $16,43 \mathrm{a}$ & $18,07 \mathrm{a}$ & $16,07 b$ & 7,87 \\
\hline \multirow[t]{3}{*}{ Número de folhas à colheita } & Primeiro & $12,52 \mathrm{a}$ & $13,41 \mathrm{a}$ & $13,72 \mathrm{a}$ & $14,35 \mathrm{a}$ & $12,08 \mathrm{~b}$ & 7,74 \\
\hline & Segundo & $12,34 \mathrm{ab}$ & $13,01 \mathrm{a}$ & $11,82 b$ & $13,61 \mathrm{a}$ & $11,18 b$ & 5,30 \\
\hline & Terceiro & $11,80 \mathrm{a}$ & $11,70 \mathrm{a}$ & $12,19 \mathrm{a}$ & $12,68 \mathrm{a}$ & $11,11 \mathrm{~b}$ & 10,13 \\
\hline \multirow[t]{3}{*}{ Área foliar $\left(\mathrm{m}^{2}\right)$} & Primeiro & $11,00 \mathrm{a}$ & $10,86 a$ & $10,31 \mathrm{a}$ & $11,70 \mathrm{a}$ & $9,75 b$ & 12,11 \\
\hline & Segundo & $15,56 \mathrm{ab}$ & $15,75 \mathrm{a}$ & $13,38 \mathrm{~b}$ & $16,13 \mathrm{a}$ & $13,66 b$ & 11,42 \\
\hline & Terceiro & $17,61 \mathrm{ab}$ & $18,47 \mathrm{a}$ & $15,26 \mathrm{~b}$ & $17,70 \mathrm{a}$ & $16,53 \mathrm{a}$ & 11,19 \\
\hline \multirow[t]{3}{*}{ Índice de área foliar } & Primeiro & $1,47 \mathrm{a}$ & $1,45 \mathrm{a}$ & $1,37 \mathrm{a}$ & $1,56 \mathrm{a}$ & $1,30 \mathrm{~b}$ & 11,70 \\
\hline & Segundo & $2,07 \mathrm{ab}$ & $2,10 \mathrm{a}$ & $1,78 \mathrm{~b}$ & $2,15 \mathrm{a}$ & $1,82 b$ & 16,19 \\
\hline & Terceiro & $2,35 \mathrm{ab}$ & $2,46 \mathrm{a}$ & $2,03 b$ & $2,36 \mathrm{a}$ & $2,20 \mathrm{a}$ & 11,57 \\
\hline
\end{tabular}

${ }^{(1)}$ Médias seguidas de letras iguais, nas linhas, não diferem entre si, pelo teste de Tukey, para os sistemas de irrigação e, pelo teste F, para os genótipos, a 5\% de probabilidade. 
número de folhas para PA42-44. Lédo et al. (2008) e Donato et al. (2009) observaram similaridade estatística entre os dois genótipos. O fato de Oliveira et al. (2008) terem conduzido seu experimento em Rio Branco, no Acre, local com alta severidade de sigatoka-negra, poderia explicar a maior retenção foliar para PA42-44 nessas condições.

A 'Prata-Anã' mostrou maior área e índice de área foliar do que PA42-44, nos dois primeiros ciclos de produção, enquanto no terceiro ciclo essas variáveis foram similares (Tabela 2).

Para as características vegetativas avaliadas, com exceção da altura da planta, comprimento e largura da terceira folha, a 'Prata-Anã' apresentou maiores valores do que PA42-44 em mais de um ciclo, independentemente dos sistemas de irrigação utilizados, o que atesta a variabilidade entre os genótipos, apesar de serem genitora e progênie, respectivamente (Donato et al., 2009). Em geral, o vigor das plantas expresso pela altura, perímetro do pseudocaule e área foliar total foi maior nos sistemas de irrigação por microaspersão e aspersão convencional, comparados ao sistema de irrigação por gotejamento, independentemente dos genótipos (Tabela 2) particularmente no segundo e terceiro ciclos. Houve exceção quanto ao número de folhas no florescimento.

A massa do cacho, no segundo ciclo, e o número de pencas, no terceiro ciclo, foram maiores em plantas cultivadas sob os sistemas de microaspersão e aspersão, comparados aos de plantas sob gotejamento (Tabela 3 ). Para as variáveis massa de pencas e massa da primeira penca, as médias sob microaspersão foram superiores às obtidas sob gotejamento, no segundo ciclo. Assim, depreende-se que a variabilidade desses caracteres não é só genética, mas também de natureza ambiental (Ortiz, 1995; Ortiz \& Vuylsteke, 1998) e de manejo, neste caso, representados pelos sistemas de irrigação.

Os maiores valores quanto às características vegetativas e de rendimento, constatados sob microaspersão e aspersão, em comparação ao gotejamento, podem advir da maior área molhada, possibilitada por aqueles sistemas, diferentemente do gotejamento (Costa et al., 2008), que proporciona maior distribuição do sistema radicular e, assim, influencia o crescimento e desenvolvimento da planta. Essa idéia encontra suporte nos trabalhos de Donato et al. (2010) e Sant'ana (2011), conduzidos na mesma área e local, em Guanambi, BA.

Sant'ana (2011) avaliou a distribuição do sistema radicular e a extração de água pela bananeira 'Prata-Anã', nas fases de florescimento do primeiro ciclo e final do crescimento dos frutos do primeiro e do segundo ciclo. $\mathrm{O}$ autor verificou maior densidade de comprimento radicular das plantas sob gotejamento e menor profundidade efetiva naquelas sob microaspersão e aspersão, o que indica que estes sistemas proporcionam

Tabela 3. Características de rendimento avaliadas em três ciclos de produção, nos genótipos de bananeira Prata-Anã e PA42-44, submetidos aos sistemas de irrigação por aspersão convencional, microaspersão e gotejamento(1).

\begin{tabular}{|c|c|c|c|c|c|c|c|}
\hline \multirow[t]{2}{*}{ Característica } & \multirow[t]{2}{*}{ Ciclo } & \multicolumn{3}{|c|}{ Sistema de irrigação } & \multicolumn{2}{|c|}{ Genótipo } & \multirow{2}{*}{$\begin{array}{l}\text { CV } \\
(\%)\end{array}$} \\
\hline & & Aspersão & Microaspersão & Gotejamento & 'Prata-Anã' & PA 42-44 & \\
\hline \multirow[t]{3}{*}{ Massa de cacho $(\mathrm{kg})$} & Primeiro & $11,97 \mathrm{a}$ & $11,21 \mathrm{a}$ & $10,88 \mathrm{a}$ & $11,35 \mathrm{a}$ & $10,72 \mathrm{a}$ & 16,72 \\
\hline & Segundo & $23,29 a$ & $24,36 \mathrm{a}$ & $19,33 b$ & $24,19 \mathrm{a}$ & $20,45 b$ & 18,00 \\
\hline & Terceiro & $22,82 \mathrm{a}$ & $23,37 \mathrm{a}$ & $22,86 \mathrm{a}$ & $23,93 \mathrm{a}$ & $22,10 \mathrm{a}$ & 14,79 \\
\hline \multirow[t]{3}{*}{ Massa de pencas $(\mathrm{kg})$} & Primeiro & $10,48 \mathrm{a}$ & $9,38 \mathrm{a}$ & $9,50 \mathrm{a}$ & $10,44 a$ & $9,43 \mathrm{a}$ & 17,52 \\
\hline & Segundo & $20,95 \mathrm{ab}$ & $21,88 \mathrm{a}$ & $17,02 b$ & $21,68 \mathrm{a}$ & $18,21 b$ & 18,28 \\
\hline & Terceiro & $20,56 \mathrm{a}$ & $20,92 \mathrm{a}$ & $20,50 \mathrm{a}$ & $21,61 \mathrm{a}$ & $19,71 \mathrm{a}$ & 15,09 \\
\hline \multirow[t]{3}{*}{ Massa da primeira penca $(\mathrm{kg})$} & Primeiro & $1,82 \mathrm{a}$ & $1,64 \mathrm{a}$ & $1,64 \mathrm{a}$ & $1,71 \mathrm{a}$ & $1,69 \mathrm{a}$ & 24,44 \\
\hline & Segundo & $2,86 \mathrm{ab}$ & $3,21 \mathrm{a}$ & $2,35 b$ & $2,84 \mathrm{a}$ & $2,77 \mathrm{a}$ & 21,28 \\
\hline & Terceiro & $2,45 \mathrm{a}$ & $2,58 \mathrm{a}$ & $2,86 \mathrm{a}$ & $2,66 \mathrm{a}$ & $2,60 \mathrm{a}$ & 20,80 \\
\hline \multirow[t]{3}{*}{ Massa da terceira penca $(\mathrm{kg})$} & Primeiro & $1,45 \mathrm{a}$ & $1,37 \mathrm{a}$ & $1,42 \mathrm{a}$ & $1,35 \mathrm{a}$ & $1,47 \mathrm{a}$ & 14,40 \\
\hline & Segundo & $2,30 \mathrm{a}$ & $2,37 \mathrm{a}$ & $2,03 \mathrm{a}$ & $2,20 \mathrm{a}$ & $2,27 \mathrm{a}$ & 16,13 \\
\hline & Terceiro & $2,10 \mathrm{a}$ & $2,07 \mathrm{a}$ & $2,32 \mathrm{a}$ & $2,07 \mathrm{a}$ & $2,26 \mathrm{a}$ & 13,07 \\
\hline \multirow[t]{3}{*}{ Número de pencas por cacho } & Primeiro & $7,33 \mathrm{a}$ & $7,32 \mathrm{a}$ & $6,93 a$ & $7,89 \mathrm{a}$ & $6,50 \mathrm{~b}$ & 10,71 \\
\hline & Segundo & $9,24 \mathrm{a}$ & $9,41 \mathrm{a}$ & $8,86 \mathrm{a}$ & $10,25 \mathrm{a}$ & $8,09 \mathrm{~b}$ & 8,61 \\
\hline & Terceiro & $10,40 \mathrm{a}$ & $11,06 \mathrm{a}$ & $9,62 b$ & $11,22 \mathrm{a}$ & $9,50 \mathrm{~b}$ & 5,70 \\
\hline
\end{tabular}

${ }^{(1)}$ Médias seguidas de letras iguais, nas linhas, não diferem, pelo teste de Tukey, para os sistemas de irrigação e, pelo teste F, para os genótipos, a 5\% de probabilidade. 
maior área com disponibilidade de água superficial, enquanto o gotejamento disponibiliza água no solo a profundidades maiores, o que facilita o aprofundamento radicular.

No primeiro ciclo, com exceção da altura de planta, que foi menor sob gotejamento, as demais características (Tabela 2) e a massa do cacho e das pencas (Tabela 3) mostraram similaridade, entre os sistemas de irrigação, independentemente dos genótipos. Possivelmente, ocorre o melhor aproveitamento da umidade e nutrientes do solo, pelas raízes, nesse sistema, em razão de sua concentração mais próxima do pseudocaule, no primeiro ciclo, o que coincide com a região de umedecimento dos gotejadores (Sant'ana, 2011). Entretanto, a partir desse período, a extensão do bulbo molhado poderá limitar a expansão horizontal do sistema radicular.

Verificaram-se massas de cacho e de pencas maiores em 'Prata Anã' do que em PA42-44, no segundo ciclo de produção (Tabela 3 ). No primeiro e terceiro ciclos, essas características não diferiram estatisticamente entre os genótipos, o que concorda com os resultados observados por Donato et al. $(2006,2009)$ e Lédo et al. (2008), pois, apesar de 'Prata-Anã' possuir maior número de pencas e frutos, PA42-44 apresenta maior massa, comprimento e diâmetro dos frutos. Oliveira et al. (2008), constataram maior massa do cacho para PA42-44, na presença de sigatoka-negra, o que possibilita afirmar que essa característica pode alterarse com a cultivar, com fatores de clima, de solo e com práticas culturais e fitossanitárias.

A 'Prata-Anã' superou o híbrido PA42-44 quanto ao número de pencas (Tabela 3 ) e de frutos (Tabela 4), nos três ciclos de produção. Esses resultados corroboram os de Donato et al. (2006, 2009), Lédo et al. (2008) e Oliveira et al. (2008), que encontraram superioridade para 'Prata-Anã' nesses caracteres, o que possibilita afirmar que a genitora possui maior número de pencas e frutos que a progênie, independentemente do ambiente e do manejo a que estejam submetidas.

O híbrido PA42-44 apresentou maior massa e diâmetro do fruto, nos dois primeiros ciclos, e maior comprimento do fruto nos três ciclos avaliados. Donato et al. (2006, 2009) e Lédo et al. (2008) encontraram resultados semelhantes, o que confirma que PA42-44 é superior nessas características, em comparação à 'Prata-Anã', e indica que são diferenças varietais que se manifestam, independentemente das condições ambientais e de manejo.
Tabela 4. Características de rendimento avaliadas em três ciclos de produção, nos genótipos de bananeira Prata-Anã e PA42-44, submetidos aos sistemas de irrigação por aspersão convencional, microaspersão e gotejamento ${ }^{(1)}$.

\begin{tabular}{lcrrr}
\hline Característica & Ciclo & \multicolumn{2}{c}{ Genótipo } & CV \\
\cline { 3 - 4 } & & 'Prata-Anã' & PA42-44 & $(\%)$ \\
\hline Número de frutos por cacho & Primeiro & $110,89 \mathrm{a}$ & $76,77 \mathrm{~b}$ & 13,48 \\
& Segundo & $166,74 \mathrm{a}$ & $124,83 \mathrm{~b}$ & 12,11 \\
& Terceiro & $184,25 \mathrm{a}$ & $153,93 \mathrm{~b}$ & 12,88 \\
\hline Massa de fruto (g) & Primeiro & $103,43 \mathrm{~b}$ & $126,79 \mathrm{a}$ & 13,01 \\
& Segundo & $133,39 \mathrm{~b}$ & $153,19 \mathrm{a}$ & 11,04 \\
& Terceiro & $132,81 \mathrm{a}$ & $140,81 \mathrm{a}$ & 9,72 \\
\hline Comprimento externo do & Primeiro & $16,05 \mathrm{~b}$ & $17,84 \mathrm{a}$ & 6,83 \\
fruto (cm) & Segundo & $18,06 \mathrm{~b}$ & $19,46 \mathrm{a}$ & 6,58 \\
& Terceiro & $17,50 \mathrm{~b}$ & $18,78 \mathrm{a}$ & 6,20 \\
\hline Diâmetro do fruto (mm) & Primeiro & $32,33 \mathrm{~b}$ & $35,69 \mathrm{a}$ & 7,80 \\
& Segundo & $32,10 \mathrm{~b}$ & $33,98 \mathrm{a}$ & 4,30 \\
& Terceiro & $32,00 \mathrm{a}$ & $32,00 \mathrm{a}$ & 3,43 \\
\hline
\end{tabular}

${ }^{(1)}$ Médias seguidas de letras iguais, nas linhas, não diferem, pelo teste $\mathrm{F}$, a $5 \%$ de probabilidade.

\section{Conclusões}

1. O sistema de irrigação por gotejamento proporciona menor vigor, expresso pelo porte e perímetro do pseudocaule, em bananeiras tipo Prata, em comparação aos sistemas de irrigação por aspersão e microaspersão.

2. A 'Prata-Anã' apresenta maior número de frutos e de pencas por cacho, e o híbrido PA42-44 apresenta maior massa, comprimento e diâmetro de frutos.

\section{Referências}

ALMEIDA, F.T.; MANTOVANI, E.C.; RAMOS, M.M.; SOARES, A.A.; MAENO, P. Eficiência de irrigação na cultura da banana no projeto Gorutuba. Revista Brasileira de Recursos Hídricos, v.8, p.187-193, 2003.

AYERS, R.S.; WESTCOT, D.W. Qualidade de água na agricultura. Campina Grande: UFPB, 1991. 208p. (Estudos FAO: irrigação e drenagem, 29).

AZEVEDO, V.F. de; DONATO, S.L.R.; ARANTES, A. de M.; MAIA, V.M.; SILVA, S. de O. e. Avaliação de bananeiras tipo Prata, de porte alto, no Semiárido. Ciência e Agrotecnologia, v.34, p.1372-1380, 2010.

COELHO, E.F.; COSTA, E.L. da; TEIXEIRA, A.H. de C.; OLIVEIRA, S.L. de. Irrigação da bananeira. Cruz das Almas: Embrapa Mandioca e Fruticultura, 2003. 8p. (Embrapa Mandioca e Fruticultura. Circular técnica, 53).

COELHO, E.F.; DONATO, S.L.R.; ANDRADE NETO, T.M. Banana. In: MONTEIRO, J.E.B.A. (Org.). Agrometeorologia 
dos cultivos: o fator meteorológico na produção agrícola. Brasília: INMET, 2009. p.321-332.

COSTA, É.L. da; COELHO, E.F.; SIMÃO, F.R.; COELHO FILHO, M.A.; OLIVEIRA, P.M. de. Irrigação da bananeira. Informe Agropecuário, v.29, p.38-46, 2008.

DESCRIPTORS for banana (Musa spp.). Roma: International Plant Genetic Resources Institute, 1996. Available at: <http://bananas. bioversityinternational.org/files/files/pdf/publications/descriptors_ en.pdf>. Accessed on: 31 May 2011.

DONATO, S.L.R.; ARANTES, A. de M.; SILVA, S. de O. e; CORDEIRO, Z.J.M. Comportamento fitotécnico da bananeira 'Prata-Anã' e de seus híbridos. Pesquisa Agropecuária Brasileira, v.44, p.1608-1615, 2009.

DONATO, S.L.R.; LÉDO, A.A.; PEREIRA, M.C.T.; COELHO, E.F.; COTRIM, C.E. Estado nutricional de bananeiras tipo Prata sob diferentes sistemas de irrigação. Pesquisa Agropecuária Brasileira, v.45, p.980-988, 2010.

DONATO, S.L.R.; SILVA, S. de O. e; LUCCA FILHO, O.A.; LIMA, M.B.; DOMINGUES, H.; ALVES, J. da S. Comportamento de variedades e híbridos de bananeira (Musa spp.), em dois ciclos de produção no sudoeste da Bahia. Revista Brasileira de Fruticultura, v.28, p.139-144, 2006.

FERNANDES, L.A.; RAMOS, S.J.; VALADARES, S.V.; LOPES, P.S.N.; FAQUIN, V. Fertilidade do solo, nutrição mineral e produtividade da bananeira irrigada por dez anos. Pesquisa Agropecuária Brasileira, v.43, p.1575-1581, 2008.

FIGUEIREDO, F.P. de.; MANTOVANI, E.C.; SOARES, A.A.; COSTA, L.C.; RAMOS, M.M.; OLIVEIRA, F.G. Produtividade e qualidade da banana Prata-Anã, influenciada por lâminas de água, cultivada no Norte de Minas Gerais. Revista Brasileira de Engenharia Agrícola Ambiental, v.10, p.798-803, 2006.

GARCIA, R.V. Sistema radicular de bananeira irrigada por aspersão convencional e microaspersão no Projeto Jaíba - MG. 2000. 47p. Dissertação (Mestrado) - Universidade Federal de Viçosa, Viçosa.

JACOMINE, P.K.T.; CAVALCANTI, A.C.; SILVA, F.B.R. e; MONTENEGRO, J.O.; FORMIGA, R.A.; BURGOS, N.; MELO FILHO, H.F.R. de. Levantamento exploratório: reconhecimento dos solos da margem direita do Rio São Francisco - Estado da Bahia. Recife: Embrapa-SNLCS: Sudene, 1979. v.2, 1296p. (Embrapa-SNLCS. Boletim técnico, 52; Sudene. Série recursos de solos, 10).

LÉDO, A. da S.; SILVA JÚNIOR, J.F. da; LÉDO, C.A. da S.; SILVA, S. de O. e. Avaliação de genótipos de bananeira na região do Baixo São Francisco, Sergipe. Revista Brasileira de Fruticultura, v.30, p.691-695, 2008.

OLIVEIRA, T.K. de; LESSA, L.S.; SILVA, S. de O. e; OLIVEIRA, J.P. de. Características agronômicas de genótipos de bananeira em três ciclos de produção em Rio Branco, AC. Pesquisa Agropecuária Brasileira, v.43, p.1003-1010, 2008.
ORTIZ, R. Plot techniques for assessment of bunch weight in banana trials under two systems of crop management. Agronomy Journal, v.87, p.63-69, 1995.

ORTIZ, R.; VUYLSTEKE, D. Quantitative variation and phenotypic correlations in banana and plantain. Scientia Horticulturae, v.72, p. 239-253, 1998.

PAULL, R.E.; DUARTE, O. Tropical fruits. $2^{\text {nd }}$ ed. Oxford: CAB International, 2011. v.1, 400p. (Crop production science in horticulturae series, 20).

ROBINSON, J.C.; GALÁN SAÚCO, V. Bananas and plantains. $2^{\text {nd }}$ ed. Oxford: CAB International, 2010. 311p. (Crop production science in horticulturae series, 19).

RODRIGUES, M.G.V.; DIAS, M.S.C.; PACHECO, D.D. Influência de diferentes níveis de desfolha na produção e qualidade dos frutos da bananeira 'Prata Anã'. Revista Brasileira de Fruticultura, v.31, p.755-762, 2009.

RODRIGUES, M.G.V.; DIAS, M.S.C.; RUGGIERO, C.; LICHTEMBERG, L.A. Planejamento, implantação e manejo do bananal. Informe Agropecuário, v.29, p.14-22, 2008.

SANT'ANA, J.A.V. do. Distribuição de raízes de bananeira 'Prata-Anã' sob diferentes sistemas de irrigação em condições semiáridas. 2011. 92p. Dissertação (Mestrado) - Universidade Federal de Lavras, Lavras.

SANTOS, H.G. dos; JACOMINE, P.K.T.; ANJOS, L.H.C. dos; OLIVEIRA, V.A. de; OLIVEIRA, J.B. de; COELHO, M.R.; LUMBRERAS, J.F.; CUNHA, T.J.F. (Ed.). Sistema brasileiro de classificação de solos. 2.ed. Rio de Janeiro: Embrapa Solos, 2006. $306 \mathrm{p}$.

SILVA, A.J.P. da; COELHO, E.F.; MIRANDA, J.H. de; WORKMAN, S.R. Estimating water application efficiency for drip irrigation emitter patterns on banana. Pesquisa Agropecuária Brasileira, v.44, p.730-737, 2009.

SILVA, S. de O.E. e; ROCHA, S.A.; ALVES, E.J.; DI CREDICO, M.; PASSOS, A.R. Caracterização morfológica e avaliação de cultivares e híbridos de bananeira. Revista Brasileira de Fruticultura, v.22, p.161-169, 2000.

SOTO BALLESTERO, M. Bananos: técnicas de produción, poscosecha y comercialización. 3.ed. San José: Litografia e Imprensa Lil, 2008. 1090p.

TAIZ, L.; ZEIGER, E. Fisiologia vegetal. 4.ed. Porto Alegre: Artmed, 2009. 848p.

YAZAR, A. Evaporation and drift losses from sprinkler irrigation systems under various operating conditions. Agricultural Water Management, v.8, p.439-449, 1984.

ZUCOLOTO, M.; LIMA, J.S. de S.; COELHO, R.I. Modelo matemático para estimativa da área foliar total de bananeira 'Prata-Anã'. Revista Brasileira de Fruticultura, v.30, p.1152-1154, 2008.

Recebido em 20 de abril de 2011 e aprovado em 7 de agosto de 2011 